\title{
Analytical Solution of Composite Curved I-Beam considering Tangential Slip under Uniform Distributed Load
}

\author{
Xu-Xi Qin $\mathbb{D}^{1},{ }^{1}$ He-Ping Chen, ${ }^{2}$ and Shu-Juan Wang ${ }^{3}$ \\ ${ }^{1}$ College of Traffic, Jilin University, Changchun 130025, China \\ ${ }^{2}$ Ingram School of Engineering, Texas State University, San Marcos, TX 78666, USA \\ ${ }^{3}$ Jilin Provincial Transport Scientific Research Institute, Changchun 130025, China \\ Correspondence should be addressed to Xu-Xi Qin; qinxx29@sina.com
}

Received 16 April 2021; Revised 26 September 2021; Accepted 16 November 2021; Published 6 December 2021

Academic Editor: Mohammad Amin Hariri-Ardebili

Copyright (C) $2021 \mathrm{Xu}$-Xi Qin et al. This is an open access article distributed under the Creative Commons Attribution License, which permits unrestricted use, distribution, and reproduction in any medium, provided the original work is properly cited.

\begin{abstract}
An analytical solution of composite curved I-beam considering the partial interaction in tangential direction under uniform distributed load is obtained. Based on the Vlasov curved beam theory, the global balance condition of the problem has been obtained by means of the principle of virtual work; integrating this by parts, the governing system of differential equations and corresponding boundary conditions have been determined. Analytical expressions for the composite beam considering the partial interaction have been developed. In order to verify the validity and the accuracy of this study, the analytical solutions are presented and compared with other three FEM results using the space beam element and the shell element. The deflection and the tangential slip of the composite curved I-beam are investigated.
\end{abstract}

\section{Introduction}

Composite curved I-beam is a structural system developed on the basis of I-girder and slab, which is composed of three main parts: I-girder beam, reinforced slab, and shear connectors. The mechanical properties of I-girder beam and slab are superior to ones when I-girder beam and slab are used alone. Therefore, the composite curved I-beam is frequently used in bridge building and shelter construction.

As early as the 1950s, Granholm [1] deduced the fundamental equations of one-dimensional linear-elastic composite beam subjected to static loads. During the same period, Newmark et al. [2] established the Newmark model for the composite beam with partial bonding action. After that, Goodman [3,4] conducted the analytical and numerical research on the relative slip between layers of composite beam and found that the relative slip between layers had a significant effect on the overall characteristics of the composite beam, with the reduction of shear connectors' stiffness. Girhammar and Gopu [5] conducted the first- and second-order analyses for the composite beam under the axial loading case. Liu et al. [6] found out the solution of shearing slip for steel-concrete composite beam under the concentrated load. Ranzi and Zona [7] modeled the reinforced concrete slab and steel joist using the Euler-Bernoulli and Timoshenko beam theory (TBT).

So far, most of the existing theories mentioned are focused on the study of straight composite beams, but few studies have been reported on curved composite beams. Thevendran et al. [8] and Shanmugam et al. [9] conducted experiments on steel-concrete composite curved beams to investigate the ultimate load behavior, while Giussani and Mola [10] developed an analytical formulation for elastic composite beams curved in-plan by assuming full interaction between the steel girder and the concrete slab. Emre and Mark [11] have proposed the finite elements for the composite beams with two-layer partial interaction by FEM (finite element method). Qin et al. [12,13] put forward the solution of the slip problem of composite curved beam by using the trigonometric series method. Zhu et al. [14] used FEM to solve the problem of composite curved beam considering slip, torsion, distortion, shear lag, and other factors. 
From the existing literature, the FEM has become the main method to study the slip of composite beams. However, FEM cannot reduce the significance of the analytical method. First, the FEM is based on the theoretical solution. Second, the advantage of the analytical method is that the calculation can be easily handled using general spreadsheet software and it is easy to be accepted by engineers. To the author's knowledge, there was no study reported on the accurate beam analytical solution of the composite curved beam accounting for the partial interaction, coupling of bending, and torsion actions. The main objective of this paper is therefore to present a beam analytical theory that considers the partial interaction in the tangential direction on the analysis of composite beams curved in-plan. The analytical solution has been validated by comparing with the FEM solutions.

\section{Basic Relations for the Slab and I-Girder}

2.1. Basic Assumptions and Conditions. The present analysis of composite curved I-beam is based on the Vlasov curved beam theory (for each part of the composite beam). Figure 1 shows a composite curved I-beam subjected to some transverse loads. The coordinate system is established as shown in Figure 1 where $z$-direction, $y$-direction, and $x$ direction represent tangential direction, vertical direction, and radial direction, respectively. The analyses are carried out on the basis of the following simplifying assumptions.

(A1) The shear connection between the girder and slab is flexible in the tangential direction, and the rigidity in the radial direction is retained. Thereby, there is a relative tangential direction slip occurring at the interface and no radial direction slip. Meanwhile, frictional effects and uplift are neglected.

(A2) The interlayer connectors located discretely are regarded as continuous. The connector load slip behavior in the tangential direction is linear-elastic with a constant slip modulus $K\left[\mathrm{~N} / \mathrm{m}^{2}\right]$ (per unit length).

(A3) Radius of curvature is constant along the beam.

(A4) The slab and girder are different linear-elastic materials; both cross-sections remain rigid throughout the deformation. The effects of shear, warping, and distortion deformation are neglected.

(A5) The bending deformation in the $x-z$ plane is neglected. The axial force of the fully composite section is ignored.

2.2. Geometry and Constitutive Relations. In this paper, the subscripts ' 1 ' and ' 2 ' refer to the slab and $I$-girder of the cross section, respectively. To introduce the displacement field for each part of the composite beam, four displacement parameters defined at the coordinate systems $x_{i}, y_{i}$, and $z_{i}(i=$ $1,2)$ are shown in Figure 2. The coordinate origin $o_{1}$ coincides with the shear centroid of slab. The coordinate origin $\mathrm{O}_{2}$ coincides with the shear centroid of the steel girder; $u_{i}$ is the tangential deflections of the cross section in the $z_{i}$ direction; $w$ is the vertical deflections in the $y_{i}$ direction; $\phi$ is

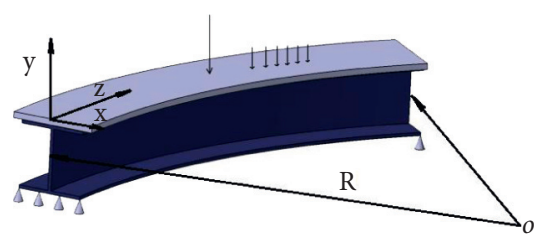

FIgURE 1: Model of a composite curved I-beam.

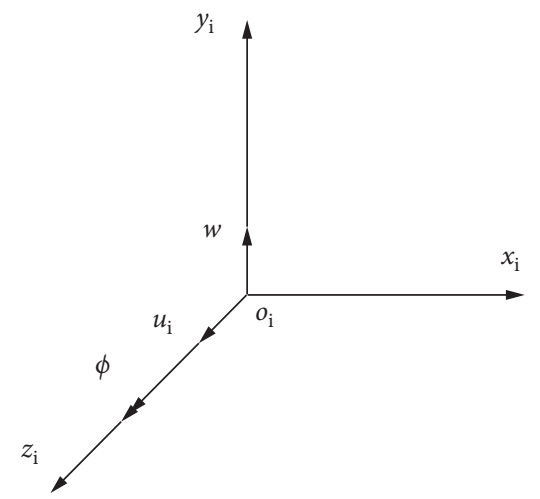

Figure 2: Displacement parameters of the composite curved Ibeam at the centroid.

the rigid body rotation about the $z_{i}$ axes. The deflection in the radial direction ( $x$-direction) $v$ is zero according to assumption A5. The deflections of the slab are $\left(w, \phi, u_{1}\right)$. The deflections of the steel girder are $\left(w, \phi, u_{2}\right)$. The geometrical relation may be written as follows. where $k_{x 1}$ and $k_{x 2}$ are the $x$-direction curvatures; $k_{z 1}$ and $k_{z 2}$ are the $z$-direction curvatures; $\varepsilon_{z 1}$ and $\varepsilon_{z 2}$ are the axial strain; and $k_{y 1}$ and $k_{y 2}$ are the $y$-direction curvatures which are zero according to assumption A5.

$$
\left.\begin{array}{rl}
k_{x i} \\
k_{z i} \\
\varepsilon_{z i}
\end{array}\right\}=\left[\begin{array}{ccc}
\frac{\mathrm{d}^{2}}{\mathrm{~d} z^{2}} & -\frac{1}{R} & 0 \\
\frac{1}{R} \frac{\mathrm{d}}{\mathrm{d} z} & \frac{\mathrm{d}}{\mathrm{d} z} & 0 \\
0 & 0 & \frac{\mathrm{d}}{\mathrm{d} z}
\end{array}\right]\left\{\begin{array}{c}
w \\
\phi \\
u_{i}
\end{array}\right\},
$$

Figure 3 shows the geometric parameters defining a cross section of a composite cured beam with two subelements of different materials where $r=r_{1}+r_{2} . r_{1}$ is distance from the centroid of the slab to the lower surface. $r_{2}$ is distance from the centroid of the girder to the upper surface. $I_{x 1}$ is the centroidal inertia moment of the slab about centroid of subelement $1(\mathrm{cg}, 1) . I_{x 2}$ is the centroidal inertia moment of the girder about centroid of subelement $2(\mathrm{cg}, 2)$. The torsional constant $J_{i}$ is calculated by the applying the thin-walled theory to the transformed section which is given by (Heins and Kuo [15]): 


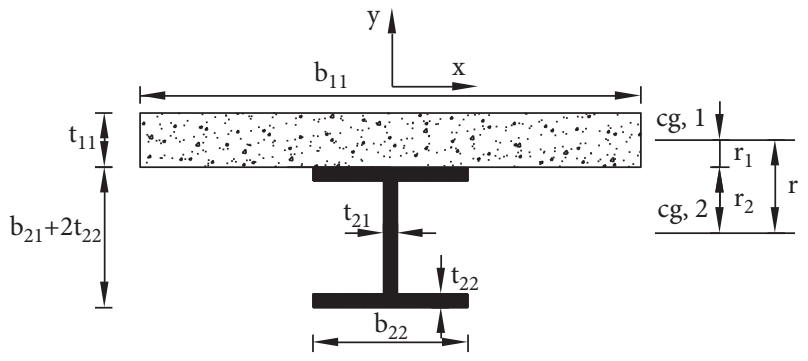

Figure 3: The cross section of the composite curved I-beam.

$$
J_{i}=\sum \frac{1}{3}\left(b_{i j} t_{i j}^{3}\right)
$$

where $j$ is the number of rectangles for every subscripts, $t_{i j}$ is the thickness of the rectangle, and $b_{i j}$ is the width of the rectangle. The physical relations are as follows:

$$
\begin{aligned}
\left\{\begin{array}{c}
M_{x i} \\
T_{i} \\
N_{i}
\end{array}\right\} & =\left[\begin{array}{ccc}
E_{i} I_{x i} & 0 & 0 \\
0 & G_{i} J_{i} & 0 \\
0 & 0 & E_{i} A_{i}
\end{array}\right]\left\{\begin{array}{c}
k_{x i} \\
k_{z i} \\
\varepsilon_{z i}
\end{array}\right\}, \\
M_{y 1} & =E_{1} I_{y 1} k_{y 1}=0 \\
M_{y 2} & =E_{2} I_{y 2} k_{y 2}=0
\end{aligned}
$$

where $N_{i}$ is the axial force; $T_{i}$ is the torque in $z$-direction; $M_{x i}$ is the bending moment in $x$-direction; and $M_{y i}$ is the bending moment in $y$-direction which is zero according to equation (2).

2.3. Basic Equations for the Slab and I-Girder. Simplify stress vectors to the shear centroid on the cross section of the slab and I-girder, respectively, as shown in Figure 4. The balance equations of the slab are as follows.

$$
\begin{aligned}
& \frac{\mathrm{d}}{\mathrm{d} z}\left\{\begin{array}{c}
N_{1} \\
Q_{y 1}
\end{array}\right\}+\left\{\begin{array}{c}
q_{z 1} \\
q_{y 1}
\end{array}\right\}+\left\{\begin{array}{c}
0 \\
-q_{0}
\end{array}\right\}=\left\{\begin{array}{l}
0 \\
0
\end{array}\right\}, \\
& \frac{\mathrm{d}}{\mathrm{d} z}\left\{\begin{array}{c}
M_{x 1} \\
T_{1}
\end{array}\right\}+\left[\begin{array}{cc}
0 & \frac{1}{R} \\
-\frac{1}{R} & 0
\end{array}\right]\left\{\begin{array}{c}
M_{x 1} \\
T_{1}
\end{array}\right\}+\left[\begin{array}{cc}
0 & -1 \\
0 & 0
\end{array}\right]\left\{\begin{array}{c}
N_{1} \\
Q_{y 1}
\end{array}\right\}+\left\{\begin{array}{c}
m_{x 1} \\
0
\end{array}\right\}=\left\{\begin{array}{l}
0 \\
0
\end{array}\right\} .
\end{aligned}
$$

The balance equations of the $I$-beam are

$$
\begin{aligned}
& \frac{\mathrm{d}}{\mathrm{d} z}\left\{\begin{array}{c}
N_{2} \\
Q_{y 2}
\end{array}\right\}+\left\{\begin{array}{c}
q_{z 2} \\
q_{y 2}
\end{array}\right\}=\left\{\begin{array}{l}
0 \\
0
\end{array}\right\}, \\
& \frac{\mathrm{d}}{\mathrm{d} z}\left\{\begin{array}{c}
M_{x 2} \\
T_{2}
\end{array}\right\}+\left[\begin{array}{cc}
0 & \frac{1}{R} \\
-\frac{1}{R} & 0
\end{array}\right]\left\{\begin{array}{c}
M_{x 2} \\
T_{2}
\end{array}\right\}+\left[\begin{array}{cc}
0 & -1 \\
0 & 0
\end{array}\right]\left\{\begin{array}{c}
N_{2} \\
Q_{y 2}
\end{array}\right\}+\left\{\begin{array}{c}
m_{x 2} \\
0
\end{array}\right\}=\left\{\begin{array}{l}
0 \\
0
\end{array}\right\},
\end{aligned}
$$

where $Q_{y i}$ is shear force in $y$-direction. The external force per unit length along the axis of the beam is indicated by $q_{0}$. According to the assumption A5, the forces $M_{y i}, Q_{x i}$, and $q_{x i}$ are neglected. Here, $m_{x i}$ is the distributed bending moment produced by shear force $q_{z i}$. Considering the equilibrium condition at the interface, there are

$$
q_{z 1}+q_{z 2}=0
$$

By eliminating $q_{z 1}+q_{z 2}$ from equations (5) and (7), one obtains

$$
N_{1}^{\prime}+N_{2}^{\prime}=0
$$

The analysis of the composite beams with interlayer slip is restricted to the case of absent axial forces, that is,

$$
N_{1}+N_{2}=E_{1} A_{1} \frac{\mathrm{d} u_{1}}{\mathrm{~d} z}+E_{2} A_{2} \frac{\mathrm{d} u_{2}}{\mathrm{~d} z}=0 .
$$

2.4. Equilibrium Condition at the Interface. Figure 5 shows the deformation conditions for the composite curved I-beam considering the longitudinal interface slip where 


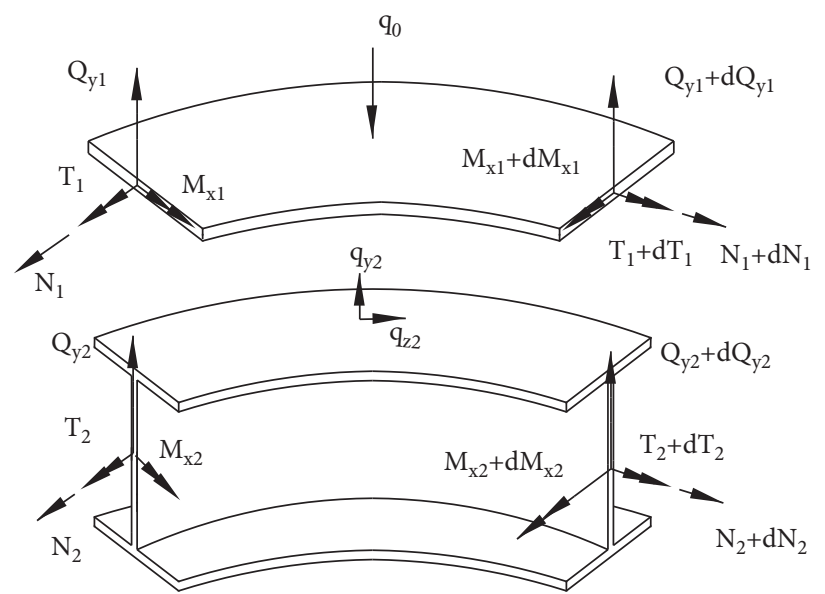

Figure 4: Force conditions of the differential element for composite curved $I$-beam.

$\kappa=\int k_{x 1} \mathrm{~d} z, r=r_{1}+r_{2}$. Considering the basic relations of the beam and the deformation conditions in Figure 5, $q_{z 1}$ can be written as follows.

$$
q_{z 1}=K \Delta u=K\left(u_{2}-u_{1}+\kappa r\right)=-N_{1}^{\prime}=N_{2}^{\prime}
$$

where $^{\prime}=(\mathrm{d} / \mathrm{d} z)$. Taking one more derivative on both sides of equation (12), with the geometrical relation $k_{x 1}=w^{\prime \prime}-$ $(\phi / R)$ and the physical relations $u_{1}^{\prime}=\left(N_{1}\right.$ $\left./ E_{1} A_{1}\right)$ and $u_{2}^{\prime}=\left(N_{2} / E_{2} A_{2}\right)$, the differential equation for the equilibrium condition at the interface then becomes

$$
E_{1} A_{1} u_{1}^{\prime \prime \prime}-\alpha^{2} E_{1} A_{1} u_{1}^{\prime}++K\left(w^{\prime \prime}-\frac{\phi}{R}\right) r=0
$$

where ()$^{\prime \prime}=\left(\mathrm{d}^{2}() / \mathrm{d} z^{2}\right) ; \quad()^{\prime \prime \prime}=\left(\mathrm{d}^{3}() / \mathrm{d} z^{3}\right) ;$ and $\alpha^{2}=K$ $\left(\left(1 / E_{2} A_{2}\right)+\left(1 / E_{1} A_{1}\right)\right)$.

\section{Governing Equations and Boundary Conditions}

3.1. Principle of Virtual Work. The governing differential equations and boundary conditions of the composite curved beam can be obtained by applying the principle of virtual work. The potential energy of the beam takes the form as follows:

$$
\delta \prod=\delta\left\{U_{M}+U_{T}+U_{a}+U_{s}+\lambda f-W\right\}=0,
$$

where $U_{M}$ is the bending strain energy due to the internal bending moments $M_{x i} ; U_{T}$ is the torsional strain energy due to the internal torsion moments $T_{x i} ; U_{a}$ is the axial strain energy due to the internal axial forces $N_{x i} ; U_{s}$ is the strain energy due to the connector deformations; $\lambda$ is a Lagrange multiplier; $f$ is the equilibrium condition at the interface corresponding to equation (13); and $W$ is the potential energy due to external loadings:

$$
\begin{aligned}
U_{M} & =\frac{1}{2} \int_{0}^{\theta} \frac{M_{x 1}^{2}}{E_{1} I_{x 1}} \mathrm{~d} z+\frac{1}{2} \int_{0}^{\theta} \frac{M_{x 2}^{2}}{E_{2} I_{x 2}} \mathrm{~d} z=\frac{1}{2} S_{I} \int_{0}^{\theta}\left[\left(w^{\prime \prime}\right)^{2}-2 w^{\prime \prime} \frac{\phi}{R}+\left(\frac{\phi}{R}\right)^{2}\right] \mathrm{d} z, \\
U_{T} & =\frac{1}{2} \int_{0}^{\theta} \frac{T_{1}^{2}}{G_{1} J_{1}} \mathrm{~d} z+\frac{1}{2} \int_{0}^{\theta} \frac{T_{2}^{2}}{G_{2} J_{2}} \mathrm{~d} z=\frac{1}{2} S_{J} \int_{0}^{\theta}\left[\left(\phi^{\prime}\right)^{2}+2 \phi^{\prime} \frac{w^{\prime}}{R}+\left(\frac{w^{\prime}}{R}\right)^{2}\right] \mathrm{d} z, \\
U_{a} & =\frac{1}{2} \int_{0}^{\theta}\left(N_{1} u_{1}^{\prime}+N_{2} u_{2}^{\prime}\right) \mathrm{d} z=\frac{1}{2} \int_{0}^{\theta} \frac{E_{1} A_{1}\left(E_{1} A_{1}+E_{2} A_{2}\right)}{E_{2} A_{2}}\left(u_{1}^{\prime}\right)^{2} \mathrm{~d} z, \\
U_{s} & =\frac{1}{2} \int_{0}^{\theta} q_{z 1} \Delta u \mathrm{~d} z=\frac{1}{2} \int_{0}^{\theta} \frac{\left(E_{1} A_{1}\right)^{2}}{K}\left(u_{1}^{\prime \prime}\right)^{2} \mathrm{~d} z, \\
\lambda f & =\int_{0}^{\theta}\left(E_{1} A_{1} u_{1}^{\prime \prime}-\alpha^{2} E_{1} A_{1} u_{1}^{\prime}++K\left(w^{\prime \prime}-\frac{\phi}{R}\right) r\right) \lambda \mathrm{d} z, \\
W & =\int_{0}^{\theta} q_{0} w \mathrm{~d} z+\int_{0}^{\theta} m_{0} \phi \mathrm{d} z+\left.\left(M w^{\prime}\right)\right|_{\varphi=0, \theta}+\left.(Q w)\right|_{\varphi=0, \theta}+\left.(T \phi)\right|_{\varphi=0, \theta},
\end{aligned}
$$


where $S_{I}=E_{1} I_{x 1}+E_{2} I_{x 2} ; S_{J}=G_{1} J_{1}+G_{2} J_{2} ; z=R \varphi$; and $\theta$ is the beam's center angle. $M, Q$, and $T$ are the total bending moment, total shear force, and total torsion moment of the beam, respectively. The displacements at the equilibrium position occur such that the potential energy of a stable system is a minimum value according to the principle of the minimum potential energy.

$$
\delta \prod=\delta\left\{\begin{array}{c}
\frac{1}{2} S_{I} \int_{0}^{\theta}\left[\left(w^{\prime \prime}\right)^{2}-2 w^{\prime \prime} \frac{\phi}{R}+\left(\frac{\phi}{R}\right)^{2}\right] \mathrm{d} z+\frac{1}{2} S_{J} \int_{0}^{\theta}\left[\left(\phi^{\prime}\right)^{2}+2 \phi^{\prime} \frac{w^{\prime}}{R}+\left(\frac{w^{\prime}}{R}\right)^{2}\right] \mathrm{d} z \\
+\frac{1}{2} \int_{0}^{\theta} \frac{E_{1} A_{1}\left(E_{1} A_{1}+E_{2} A_{2}\right)}{E_{2} A_{2}}\left(u_{1}^{\prime}\right)^{2} \mathrm{~d} z+\frac{1}{2} \int_{0}^{\theta} \frac{\left(E_{1} A_{1}\right)^{2}}{K}\left(u_{1}^{\prime \prime}\right)^{2} \mathrm{~d} z \\
+\int_{0}^{\theta}\left(E_{1} A_{1} u_{1}^{\prime \prime}-\alpha^{2} E_{1} A_{1} u_{1}^{\prime}+K\left(w^{\prime \prime}-\frac{\phi}{R}\right) r\right) \lambda \mathrm{d} z \\
-\int_{0}^{\theta} q_{0} w \mathrm{~d} z-\int_{0}^{\theta} m_{0} \phi \mathrm{d} z-\left.\left(M w^{\prime}\right)\right|_{\varphi=0, \theta}-\left.(Q w)\right|_{\varphi=0, \theta}-\left.(T \phi)\right|_{\varphi=0, \theta}
\end{array}\right\} .
$$

The coupled governing equations for the composite beam are as follows after taking the variation:

$$
\left[\begin{array}{ccc}
S_{I} \frac{\mathrm{d}^{4}}{\mathrm{~d} z^{4}}-\frac{S_{J}}{R^{2}} \frac{\mathrm{d}^{2}}{\mathrm{~d} z^{2}} & -\frac{S_{I}+S_{J}}{R} \frac{\mathrm{d}^{2}}{\mathrm{~d} z^{2}} & K r \frac{\mathrm{d}^{2}}{\mathrm{~d} z^{2}} \\
r \frac{\mathrm{d}^{2}}{\mathrm{~d} z^{2}} & -\frac{1}{R} & \frac{\mathrm{d}^{2}}{\mathrm{~d} z^{2}}-\alpha^{2} \\
-\frac{S_{I}+S_{J}}{R} \frac{\mathrm{d}^{2}}{\mathrm{~d} z^{2}} & -S_{J} \frac{\mathrm{d}^{2}}{\mathrm{~d} z^{2}}+\frac{S_{I}}{R^{2}} & -\frac{K r}{R}
\end{array}\right]\left\{\begin{array}{c}
w \\
\phi \\
\lambda
\end{array}\right\}=\left\{\begin{array}{c}
q_{0} \\
0 \\
m_{0}
\end{array}\right\} .
$$

The pertaining boundary conditions are

$$
\begin{gathered}
{\left.\left[S_{I}\left(w^{\prime \prime}-\frac{\phi}{R}+\frac{K}{S_{I}} \lambda\right)-M\right] \delta w^{\prime}\right|_{0} ^{\theta}=0} \\
{\left.\left[S_{J}\left(\phi^{\prime}+\frac{w^{\prime}}{R}\right)-T\right] \delta \phi\right|_{0} ^{\theta}=0} \\
{\left.\left[S_{I}\left(w^{\prime \prime \prime}-\frac{\phi^{\prime}}{R}+\frac{K}{S_{I}} \lambda^{\prime}\right)+S_{J}\left(\frac{\phi^{\prime}}{R}+\frac{w^{\prime}}{R^{2}}\right)-Q\right] \delta w\right|_{0} ^{\theta}=0} \\
\left.\left(\frac{\left(E_{1} A_{1}\right)^{2}}{K} u_{1}^{\prime \prime}-E_{1} A_{1} \lambda^{\prime}\right) \delta u_{1}^{\prime}\right|_{0} ^{\theta}=0 \\
\left.E_{1} A_{1}\left[\frac{\left(E_{1} A_{1}+E_{2} A_{2}\right)}{E_{2} A_{2}} u_{1}^{\prime}+\lambda^{\prime \prime}-\alpha^{2} \lambda-\frac{E_{1} A_{1}}{K}\left(u_{1}^{\prime \prime}\right)\right] \delta u_{1}\right|_{0} ^{\theta}=0 .
\end{gathered}
$$

According to equations (18)-(23), one can get

$$
\begin{aligned}
& M=E I\left(w^{\prime \prime}-\frac{\phi}{R}+\frac{K r}{E I} \lambda\right), \\
& T=G I_{d}\left(\phi^{\prime}+\frac{w^{\prime}}{R}\right), \\
& Q=\frac{\mathrm{d} M}{\mathrm{~d} z}+\frac{T}{R}, \\
& \lambda=\frac{E_{1} A_{1} u_{1}^{\prime}}{K}=\frac{N_{1}}{K} .
\end{aligned}
$$

It can be seen that $\Delta u=-\lambda^{\prime}$ from equations (12) and (27).

3.2. Boundary Conditions. Table 1 shows the common boundary conditions.

\section{The Solution of the Composite Curved Beam under Uniform Distributed Load}

The coupled governing equations for the composite beam are the linear differential equations of constant coefficient group. According to Cramer's rule, the determinant for equation (17) can be written as

$$
\xi_{i}^{2}\left(1+R^{2} \xi_{i}^{2}\right)^{2}\left(\xi_{i}^{2} S_{I}-\alpha^{2} S_{I}-K r^{2}\right)=0 .
$$

The eigenvalues $\xi_{i}(i=1,2, \ldots, 8)$ can be calculated as

$$
\begin{aligned}
& \xi_{1}=-\xi_{2}=\eta=\sqrt{\alpha^{2}+\frac{K r^{2}}{S_{I}}}, \\
& \xi_{3}=\xi_{4}=-\xi_{5}=-\xi_{6}=\frac{i}{R}, \\
& \xi_{7}=\xi_{8}=0 .
\end{aligned}
$$

So, the general solution of the differential equation (17) can be expressed as follows: 


$$
u=B a+u_{p}
$$

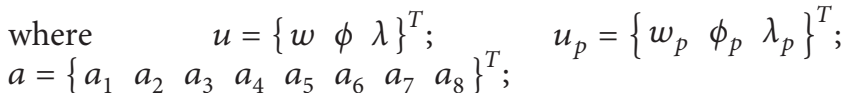

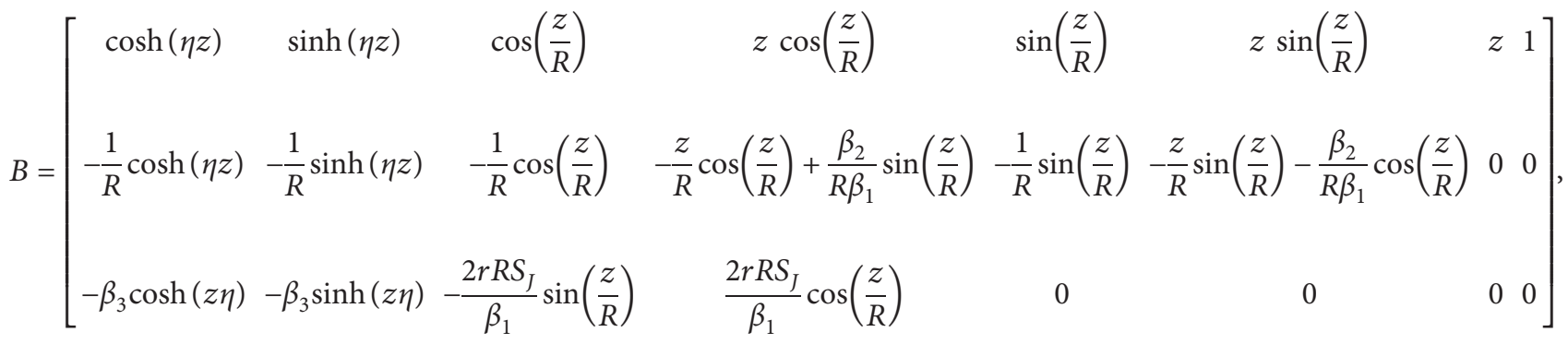

$$
\begin{aligned}
& \beta_{1}=K r^{2} R^{2}+\left(1+R^{2} \alpha^{2}\right)\left(S_{J}+S_{I}\right) \text {, } \\
& \beta_{2}=-2 R\left(S_{I}+S_{I} R^{2} \alpha^{2}+K r^{2} R^{2}\right) \text {, } \\
& \beta_{3}=\frac{S_{I}\left(1+R^{2} \eta^{2}\right)}{K r R^{2}} .
\end{aligned}
$$

The constants $\left(a_{1} \cdots a_{8}\right)$ depend on the boundary conditions. It is easy to find a particular solution when a curved beam is subject to a uniform load.

$$
\begin{aligned}
& w_{p}=-\frac{k R^{2}}{2 S_{I}} q z^{2}, \\
& \phi_{p}=-\frac{(1+k) q R^{3}}{S_{I}}+\frac{K q R^{3} r^{2}}{S_{I}^{2} \eta^{2}}, \\
& \lambda_{p}=\frac{q r R^{2}}{S_{I} \eta^{2}}
\end{aligned}
$$

where $k=\left(S_{I} / S_{J}\right)$. The coefficients are given in Appendix for a statically indeterminate composite curved I-beam with rigid torsion constraints in both ends. For other loads, one can solve the corresponding problem as long as one finds the special solution and the general solution according to the common boundary conditions in Table 1 .

\section{Numerical Examples}

A steel-concrete composite curved I-beam subjected to a uniform load is taken as a numerical example. The central angle of the beam is $\theta=(\pi / 6)$, and the curvature radius is $24 \mathrm{~m}$. Overall height of the steel girder $b_{21}=358 \mathrm{~mm}$, a flange width $b_{22}=300 \mathrm{~mm}$, a flange thickness $t_{22}=16 \mathrm{~mm}$, and a web thickness $t_{21}=10 \mathrm{~mm}$. The material properties of steel are the modulus of elasticity $E_{s}=206 \mathrm{GPa}$ and Poisson's ratio is $\mu_{s}=0.3$. The concrete slab width $b_{11}=1000 \mathrm{~mm}$, and thickness $t_{11}=100 \mathrm{~mm}$. The material properties of concrete are the modulus of elasticity $E_{c}=$ $35 \mathrm{GPa}$ and Poisson's ratio $\mu_{c}=0.2$. The mass density of the steel material is $7850\left(\mathrm{~kg} / \mathrm{m}^{3}\right)$ and that of concrete material is $2400\left(\mathrm{~kg} / \mathrm{m}^{3}\right)$ which produce a total distributed vertical load of $3400(\mathrm{kN} / \mathrm{m})$ along the beam.

Three different finite element models of the steel-concrete composite curved $I$-beam were investigated to determine the validity of the analytical solution. In the first model, both the concrete slab and steel girder are modeled as space beam element (Figure 6(a)). The second model is based on the research of Yazdan Majdi et al. [16]. The concrete slab is idealized as quadrilateral shell element with six degrees of freedom, and the steel girder is modeled as space beam element (Figure 6(b)). In the third model [17], both the concrete slab and the steel girder are modeled as shell elements (Figure 6(c)).

In all three FEM models, the connection between the plate and beam is modeled by applying two rigid links as shown in Figure 6. The multiple-point constraints (MPCs) are adopted to keep the connection between the rigid link of the slab and the rigid link of the girder through interface nodes. And the spring elements are used in tangential direction to allow the possibility of moving along the tangential direction. Coupling degrees of freedom $w$ are used to prevent uplifting. Coupling degrees of freedom $v$ are used to prevent the slip in the radial direction.

The finite element program ANSYS is used to model the described beam. The beam is a statically indeterminate with rigid torsion constraints in both ends as shown in Figure 7. The vertical deflection $w$, radial deflection $u$, radial direction deflection $v$, as well as torsional deflection $\phi$ are restrained to satisfy the rigid torsion constraints at both ends. Beam4, shell63, and MPC184 are chosen as the space beam element, shell element, and multiple-point constraints element, respectively. Here, COMBIN14 is used when considering tangential slip. Table 2 shows the number of the elements for the three different finite element models. 


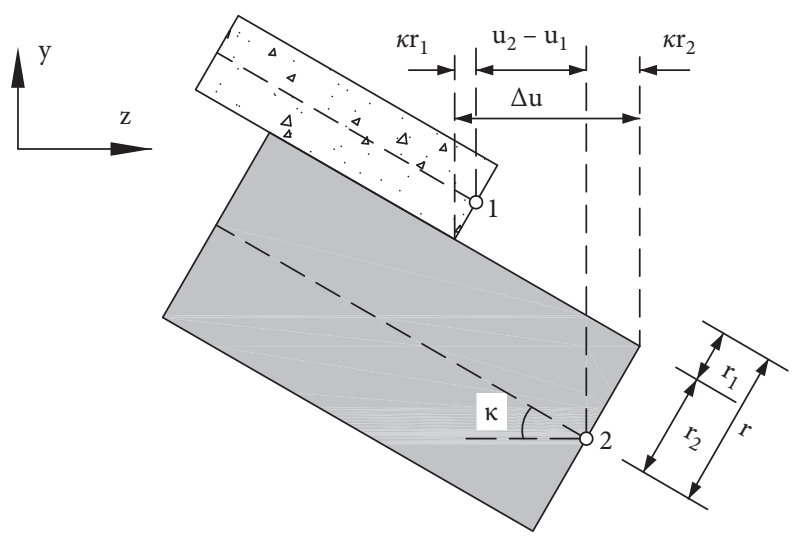

FIGURE 5: Deformation conditions of the differential element for the composite curved $I$-beam in $y$ - $z$ plan.

TABLE 1: Common support conditions.

The boundary conditions
$\begin{aligned} & \lambda=0 \\ & M=0\end{aligned}$
Fixed end

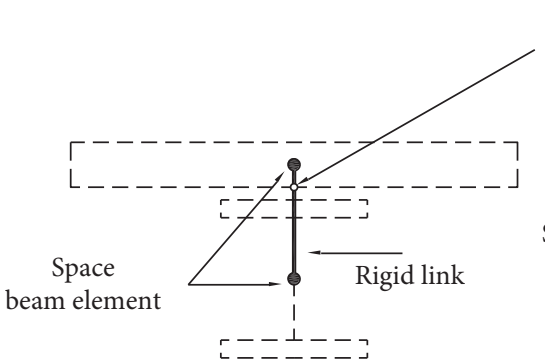

(a) beam model

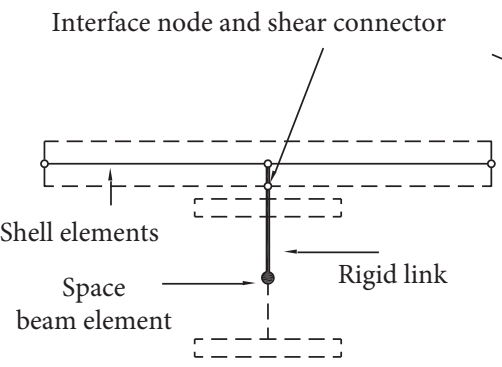

(b) beam-shell model

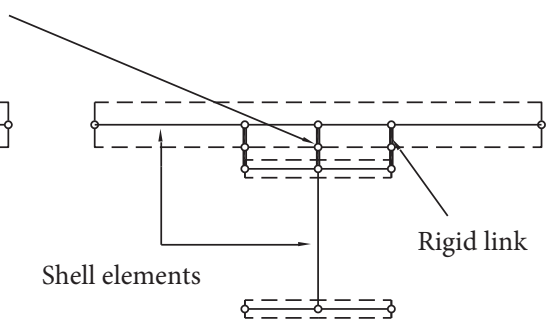

(c) shell model

Figure 6: Three finite element models for the composite curved I-beam with partial interaction in the radial direction: (a) beam model; (b) beam-shell model; (c) shell model.

The $K=0$ interaction case was investigated first. According to the coefficient in Appendix, the solution degenerates into the classic solution of Vlasov curved beam when the stiffness in the tangential direction $(K=0)$ is zero. Figures 8-10 show the vertical deflection, torsional angle, and tangential slip obtained by the finite element method and the results using the proposed method, respectively. From Figures 8-10, we can see that the results are quite close.

Figures 11 and 12 show the midspan vertical deflection and the midspan torsional angle when the stiffness of the shear connecter is changed, respectively. The results show that the performance of the curved composite $I$-beam becomes significantly rigid when the shear connector's stiffness is increased from $10^{5}$ to $10^{9}$. The reduction of shear connectors' stiffness between layers has a significant effect on the midspan vertical deflection and torsional angle.

As shown in Figures 11-12, the calculation results of three finite element models are obtained. At the $x$-axis coordinate point 1 in Figure 11, the relative errors are $-0.26 \%, 2.4 \%$, and $3.48 \%$ between this paper and shell, 


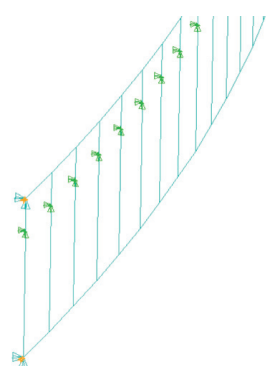

(a)

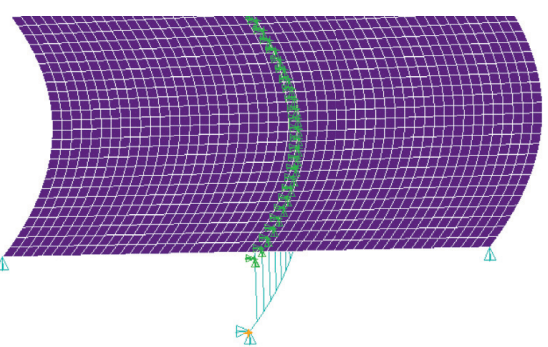

(b)

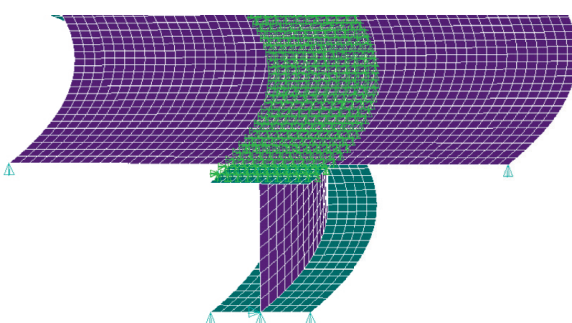

(c)

FiguRE 7: ANSYS constraint condition for the three composite beam models at one end: (a) beam model; (b) beam-shell model; (c) shell model.

TABLE 2: The number of the elements for the different finite element models.

\begin{tabular}{lcccc}
\hline Type/number & Beam4 & Shell63 & MPC184 & COMBIN14 \\
\hline Beam model & 120 & 0 & 122 & 60 \\
Beam-shell model & 60 & 3000 & 122 & 60 \\
Shell model & 0 & 4800 & 1342 & 671 \\
\hline
\end{tabular}

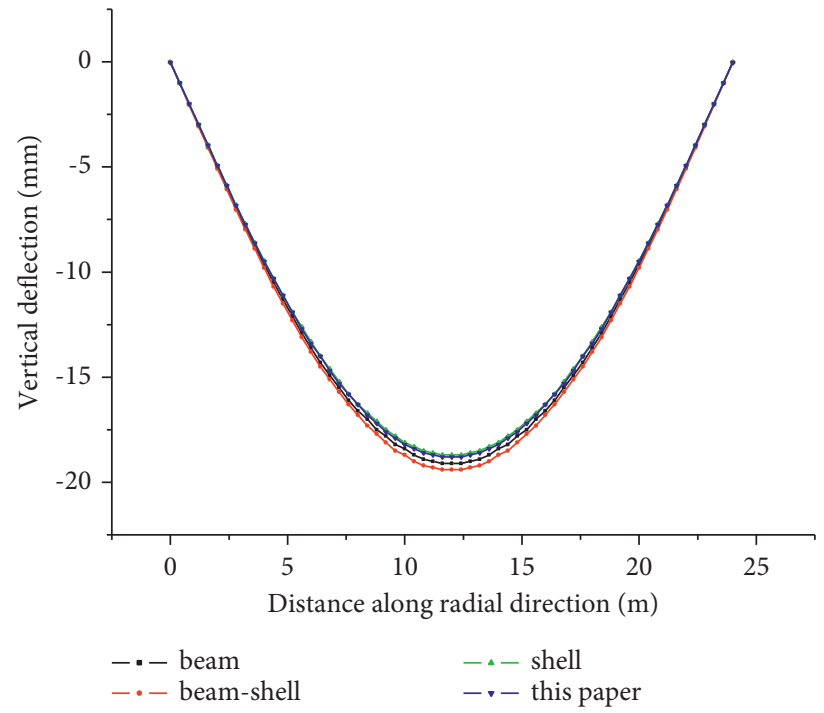

FIgURE 8: Vertical deflection for the steel-concrete composite curved $I$-beam with $K=0$.

beam-shell, and beam models, respectively. In Figure 12, the relative errors are $0.28 \%, 1.69 \%$, and $2.68 \%$ between this paper and shell, beam-shell, and beam results, respectively. The beam finite element model and beam-shell finite element model are simplified models of the composite curved I-beam. So, these two finite element model results are not as accurate as shell model results. It can be seen that the results of this paper are closest to the shell model. Thus, this paper model is sufficient for practical purposes. 


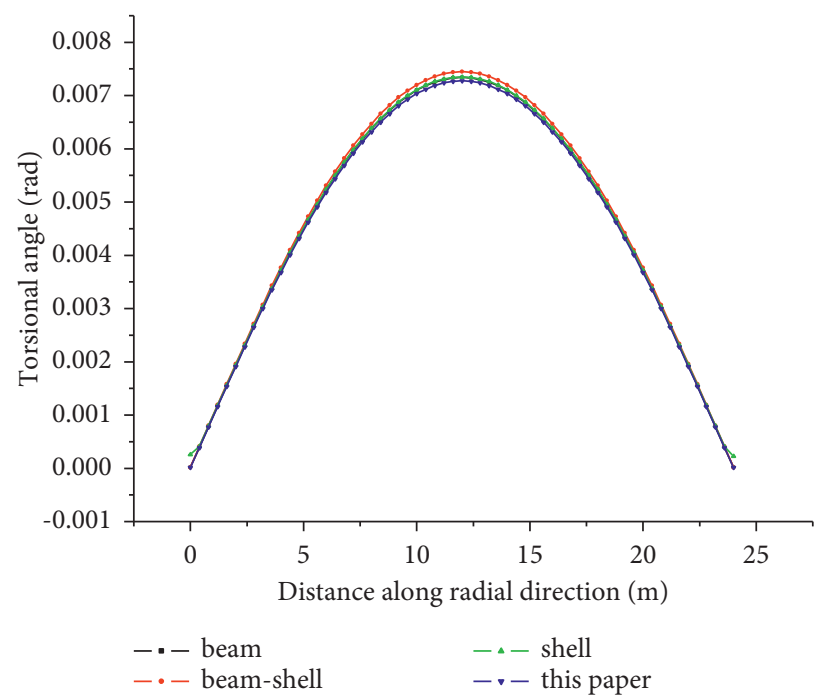

FIgURE 9: Torsional angle for the steel-concrete composite curved $I$-beam with $K=0$ and composite curved $I$-beam with $K=0$.

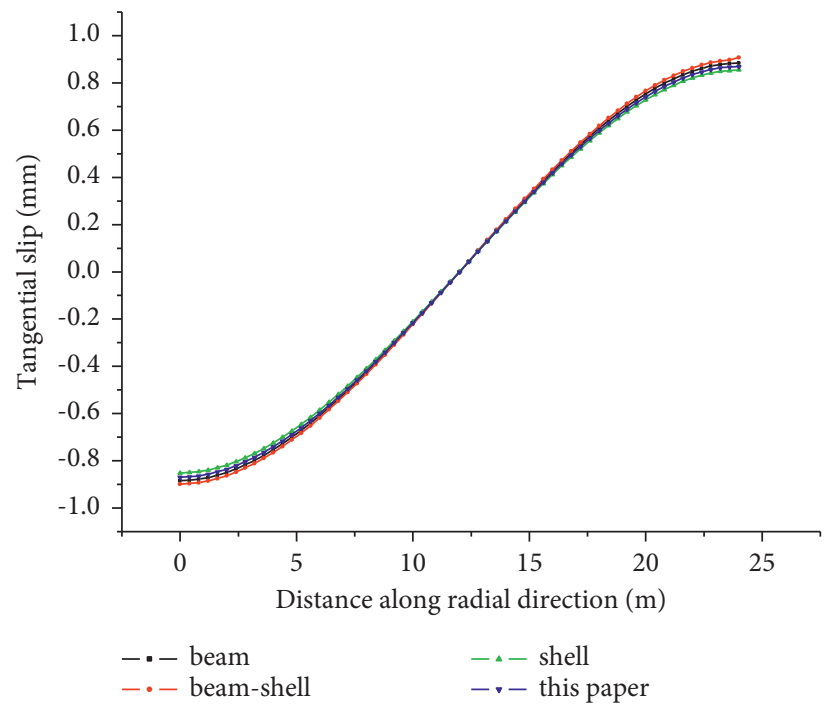

FIGURE 10: Tangential slip for the steel-concrete composite curved $I$-beam with $K=0$. 


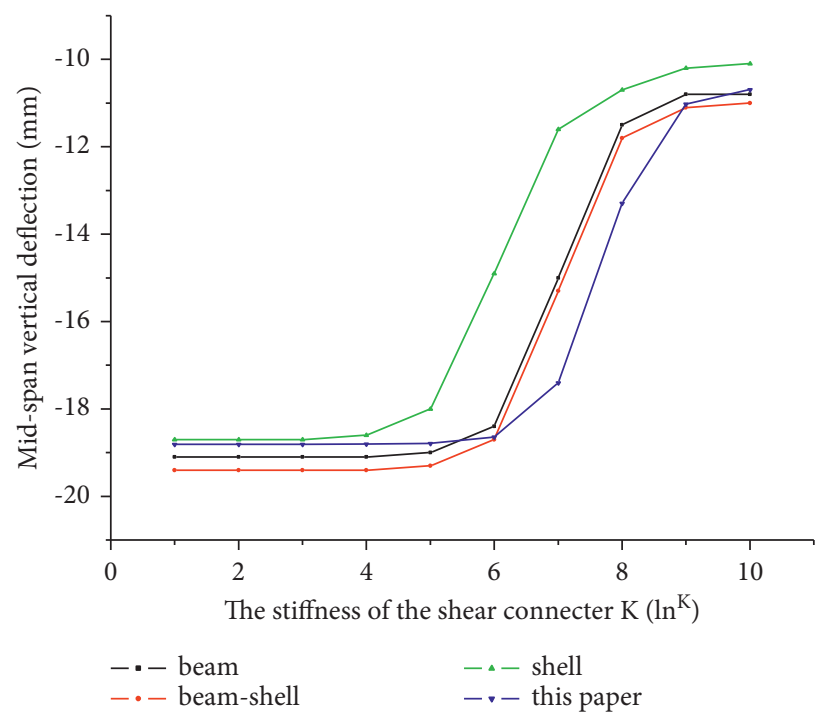

Figure 11: Vertical deflection at midspan when the stiffness of the shear connecter is change of the shear connecter change.

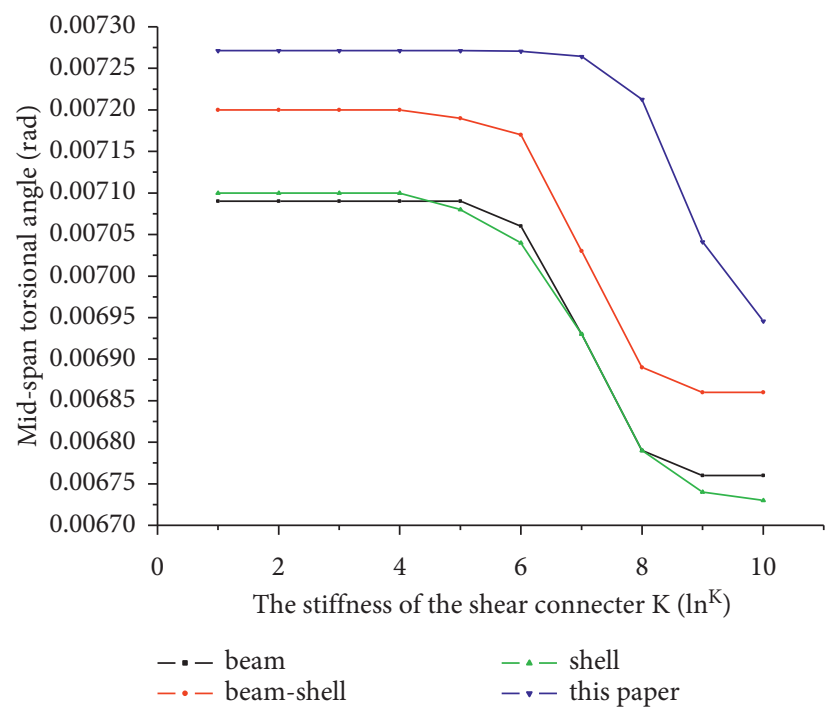

Figure 12: Torsional angle at midspan when the stiffness of the shear connecter is change of the shear connecter change.

\section{Conclusions}

An analytical solution of composite curved I-beam is presented based on both the Vlasov curved beam theory and the principle of linearized virtual work considering the partial interaction in tangential direction. The following issues concerning the new analytical solution deserve attention:

(a) Comparisons between three FEM numerical results and the analytical solutions indicate that the developed equations are efficient and accurate to describe the mechanical behavior of the composite curved $I$-beam with slip in the tangential direction

(b) The results of the shear connection variation example show that the curved composite I-beam becomes significantly rigid when the shear connecter's stiffness is increased (c) The partial interaction between the slab and girder should be taken into consideration since the full interaction assumption may significantly overestimate the stiffness of the curved composite I-beam

\section{Recommendations}

The established beam theory is the theory that two composite materials are combined by elastic connection. Therefore, it provides a theoretical idea for the related research of some functionally graded composite beams $[18,19]$ and some sandwich structures [20]. In addition, only a relative tangential direction slip is considered in this paper. As a matter of fact, radial direction slip is not zero if the shear connection between the girder and slab is flexible but remains stiffness in the radial direction. Therefore, a formulation for the elastic 
analysis of composite curved $I$-beam with the tangential direction slip and the radial direction slip needs to be developed in the future work.

\section{Appendix}

$$
\begin{aligned}
& a_{1}=\frac{K q r^{2} R^{4}}{S_{I}^{2} \eta^{2}\left(1+R^{2} \eta^{2}\right)^{2}}, \\
& a_{2}=\frac{-K q r^{2} R^{4} \tanh (R \eta \theta / 2)}{S_{I}^{2} \eta^{2}\left(1+R^{2} \eta^{2}\right)^{2}}, \\
& a_{3}=\frac{-q(1+2 k) R^{4}}{S_{I}}+\frac{K q R^{6} r^{2}\left(2+R^{2} \eta^{2}\right)}{S_{I}^{2}\left(1+R^{2} \eta^{2}\right)^{2}}, \\
& a_{4}=\frac{q(1+k) R^{3} \tan (\theta / 2)}{2 S_{I}}-\frac{K q r^{2} R^{5} \tan (\theta / 2)}{2 S_{I}^{2}\left(1+R^{2} \eta^{2}\right)}, \\
& a_{5}=\frac{q R^{4} \sec ^{2}(\theta / 2)((1+k) \theta-2(1+2 k) \sin \theta)}{4 S_{I}}+\frac{K q R^{4} r^{2} \sec ^{2}(\theta / 2)\left(2 R^{2}\left(2+R^{2} \eta^{2}\right) \sin (\theta)-R^{2}\left(1+R^{2} \eta^{2}\right) \theta\right)}{4 S_{I}^{2}\left(1+R^{2} \eta^{2}\right)^{2}}, \\
& a_{6}=\frac{-q(1+k) R^{3}}{2 S_{I}}+\frac{K q r^{2} R^{5}}{2 S_{I}^{2}\left(1+R^{2} \eta^{2}\right)}, \\
& a_{7}=\frac{q k R^{3} \theta}{2 S_{I}}, \\
& a_{8}=\frac{q(1+2 k) R^{4}}{S_{I}}-\frac{K q r^{2} R^{4}}{S_{I}^{2} \eta^{2}},
\end{aligned}
$$

where $k=\left(S_{I} / S_{J}\right)$.

\section{Data Availability}

The established finite element model and the example data solved in this paper are provided by the authors if necessary.

\section{Conflicts of Interest}

The authors declare that they have no conflicts of interest.

\section{References}

[1] H. Granholm, "On composite beams and columns with special regard to nailed timber structures," Technical Report 88 Sweden, Chalmers Univeristy of Technology, Gothenburg, Sweden, 1949, in Swedish.

[2] N. M. Newmark, C. P. Seiss, and I. M. Veist, "Tests and analysis of composite beams with incomplete interactions," Proceedings of the Society for Experimental Stress Analysis, vol. 4, no. 1, pp. 75-92, 1951.

[3] J. R. Goodman and E. P. Popov, "Layered beam systems with interlayer slip," Journal of the Structural Division, vol. 94, no. 11 , pp. 2535-2548, 1968.

[4] J. R. Goodman and E. P. Popov, "Layered wood systems with inter-layer slip," Wood Science, vol. 1, no. 3, pp. 148-158, 1969.
[5] U. A. Girhammar and V. K. A. Gopu, "Composite beamcolumns with interlayer slip-exact analysis," Journal of Structural Engineering, vol. 119, no. 4, pp. 1265-1282, 1993.

[6] H. B. Liu, W. H. Liu, and Y. L. Zhang, "Calculation analysis of shearing slip for steel-concrete composite beam under concentrated load," Applied Mathematics and Mechanics, vol. 26, no. 6, pp. 735-740, 2005.

[7] A. Zona and G. Ranzi, "Finite element models for nonlinear analysis of steel-concrete composite beams with partial interaction in combined bending and shear," Finite Elements in Analysis and Design, vol. 47, no. 2, pp. 98-118, 2011.

[8] V. Thevendran, N. E. Shanmugam, S. Chen, and J. Y. R. Liew, "Experimental study on steel-concrete composite beams curved in plan," Engineering Structures, vol. 22, no. 8, pp. 877-889, 2000.

[9] N. E. Shanmugam, M. Mahendrakumar, and V. Thevendran, "Ultimate load behaviour of horizontally curved plate girders," Journal of Constructional Steel Research, vol. 59, no. 4, pp. 509-529, 2003.

[10] F. Giussani and F. Mola, "Service-stage analysis of curved composite steel-concrete bridge beams," Journal of Structural Engineering, vol. 132, no. 12, pp. 1928-1939, 2006.

[11] R. E. Erkmen and M. A. Bradford, "Nonlinear elastic analysis of composite beams curved in-plan," Engineering Structures, vol. 31, no. 7, pp. 1613-1624, 2009. 
[12] Q. Xu-Xi, L. H. Bing, L. Han-Bing, W. Chun-Li, and G. Zheng-Wei, "A trigonometric analytical solution of simply supported horizontally curved composite I-Beam considering tangential slips," Mathematical Problems in Engineering, vol. 2016, Article ID 2465025, 12 pages, 2016.

[13] X.-X. Qin, H.-B. Liu, C.-L. Wu, and G. Zheng-wei, "Semianalytical solution of horizontally composite curved I-beam with partial slip," Steel and Composite Structures, vol. 27, no. 1, pp. 1-12, 2018.

[14] Li Zhu, K. L. Su Ray, and M. J. Li, "Finite beam element with 26 DOFs for curved composite box girders considering constrained torsion, distortion, shear lag and biaxial slip," Engineering Structures, vol. 232, pp. 1-26, 2021.

[15] C. P. Heins and J. T. C. Kuo, "Torsional properties of composite girders," Engineering Journal, vol. 9, no. 2, pp. 79-85, 1972.

[16] Y. Majdi, C.-T. T. Hsu, and M. Zarei, "Finite element analysis of new composite floors having cold-formed steel and concrete slab," Engineering Structures, vol. 77, no. 15, pp. 65-83, 2014.

[17] W. Chung and E. D. Sotelino, "Three-dimensional finite element modeling of composite girder bridges," Engineering Structures, vol. 28, no. 1, pp. 63-71, 2006.

[18] R. Zerrouki, A. Karas, M. Zidour et al., "Effect of nonlinear FG-CNT distribution on mechanical properties of functionally graded nano-composite beam," Structural Engineering and Mechanics, vol. 78, no. 2, pp. 117-124, 2021.

[19] A. Bakoura, F. Bourada, A. A. Bousahla et al., "Buckling analysis of functionally graded plates using HSDT in conjunction with the stress function method," Computers and Concrete, vol. 27, no. 1, pp. 73-83, 2021.

[20] N. Bendenia, M. Zidour, A. A. Bousahla et al., "Deflections, stresses and free vibration studies of FG-CNT reinforced sandwich plates resting on Pasternak elastic foundation," Computers and Concrete, vol. 26, no. 3, pp. 213-226, 2020. 